\title{
$\sqrt{ }$ Consideraciones sobre Derecho Indiano Jorge Basadre Ayulo
}

\section{ELEMENTOS Y VINCULOS FORMATIVOS DEL DERECHO PERUANO EN SU EVOLUCION HISTORICA}

E L SISTEMA JURIDICO peruano a travis de su evolución y no como una sucesión de etapas desvinculadas entre sí o en compartimientos separados entre sf. La propia denominación del curso universitario de Historia del derecho peruano lleva inserta la noción de una unidad más o menos estable y continuada de este sistema jurídico a lo largo de su azarosa existencia. En una posición diferente, el jurista mexicano Toribio Esquivel Obregón se ha referido a una variedad de sistemas jurídicos mexicanos en su libro "Apuntes para la historia del Derecho en México" y que ha sido reimpreso en el afio de 1984. (1) (2)

(1) "El estudio de ln historia del Derecho en México debe abordatse desde los diferentes puntot como antecedentes de la evolación que comenzó al sargir la Nueva España, par la unión a convivencia de la raza españole con la aborigen". Toribio Esquivel Obregán, Apuntes para la histaria del Derecho en Mésica. Méxice, 1984, Primer volumen, p, 3.

(2) La primera edición det llbre de Esquivet Obregón, en 4 tomos, fue impresa entre 18371949.

Sobre la obra de Tonibio Esquivel Obregán pueden consultarse G.F, Margrandt, "Móxioo: 75 athos de investización historrics jaridica", $L X X V$ atos de evolución turialica del munda Volumen 11, México UNAM, 1979. También pueden cossultarse: G,M Gonziltez, Toribio Esqutrel Obvegów, actirud e ideario politica. Mexico, 1967. Entre los estudios peruanos están Jorge Basadre Grohmann. "Apuntes para la historia del Derecho en México" en Revista de Derecho y Clencles Politicas, sño IV, númeto III, p. 503-504. Lima, tesetr trimestre, 1940. 
1.1. El curso universitario de historia del derecho peruano se expone con doble criterio: nacional y comparado y su inicio se traza con el sistema juridico que aparece en los Andes peruanos desde los siglos XI y XII, con el aporte de diversas culturas que la precedieron. Por esta razón, nos es útil formular la interrogante del itinerario de viaje que vamos a efectuar en la búsqueda de los sistemas juridicos del remoto pasado. Y la respuesta que parece surgir es la siguiente: la ruta será hasta el momento en que podamos conocer este pasado y estemos en capacidad de reconstruirlo mediante el uso de fuentes idóneas. $\mathrm{Y}$, este viaje a los misterios del ayer, por un túnel imaginario que nos conduce al pasado, lo vamos a efectuar hasta el periodo prehispano a despecho de la afirmación de que la historia implica el conocimiento de la escritura (3) (4).

1.2. Este derecho prehispánico, andino peruano (con su eje central en los Andes de lo que hoy es república peruana) constituye un sistema diferente en su noción medular, en su formación, en su desarrollo y en su aplicación. Estas normas jurídicas aborigenes son notoriamente distintas a las que rigen hoy al propio derecho castellano concedido en el siglo XVI. Pero, es de destacarse que esas normas juridicas prehispánicas estaban constituidas por normas iguales para casos iguales, las que tenian carácter mandatorio y que no fue aniquilado con la imposición de un nuevo derecho, sino "recreado" por el derecho occidental.

La norma jurídica incaica tenia los siguientes tres caracteres esenciales: imperatividad, universalidad y obligatoriedad. $\mathrm{Y}$ el maestro sanmarquino doctor Jorge Basadre Grohmann mencionaba en el dictado de sus clases sanmarquinas que el Derecho aborigen peruano era diferente en su estructura, en su esencia y en su mundo cultural propio que lo distingue de cualquier sistema que apareció con posterioridad (5).

También, sobee la Ǵltima edición en el libro de Esquivel Obregón estrí Jorge Basadre Ayule. Esquivel Obregún, Toribio, "Apuntes para la historia del Derecho". Seganda edición. Editorial Porrúa, Mexico 1984. Dos volúmenes en lus et pnuxis, númeto 14, diciembre 1989, P.
$229-300$.

(3) En Chite, se enumeran dos períodos fundementales: et Indiano y el Nacional o Patrio. Jaime Eyzaguire. Historia del Derecho. Santiago, 1980, p. 18 (Hay ediciones postetiores). Se recusa el estudio del sistena ptehispánico.

(4) "El Derecho indigena es de orién peruano y sutóctono. .. Su aportacióa resulta en conjun to infiesa". Jaime Eyzaguitre, op. cit., D. 19.

(5) Jorge Dasadre Grohmann. Coptos del Curso de historia del Derecho periasno. Fecuttad de Derecho de la Universidad Nacianal Mayer de Sun Marcos. Versianes tequíerificas del curso. AAto 1944. p. 29. 
La extensión del curso de historia del Derecho peruano en el tiempo se retrotrae hasta las culturas preincas y la inca a despecho de otros sistemas como el argentino (6). Y la convivencia de formas de vida distintas a la preincaica e incaica con relación al Derecho peruano se demuestra con el estudio, por ejemplo, de la comunidad agraria, de las instituciones familiares, el régimen administrativo, la ejecución de las penas por un Estado despótico. No vamos a encontrar normas jurisdiccionales ni garantías individuales o colectivas como las que aparecieran en el siglo XVI y con posterioridad a éste. Así, existieron como organismos con fuerza jurisdiccional entre los pueblos preíncas los consejos de las comunidades y la autoridad semi-despotica de los curacas. Estos son mantenidos por las autoridades incaicas en algunos casos con facultades restringidas. $\mathrm{Y}$ en las disputas de tierras se llamaba a los funcionarios imperiales para evitar los sangrientos conflictos bélicos en el imperio. $\mathrm{Y}$ estos funcionarios también intervienen para reprimir los delitos más graves. $\mathbf{Y}$, además, el derecho incaico creó una responsabilidad de los curacas por las violaciones de sus propios subordinados, como en los casos de diferencias o excesos en la recaudación de tributos.

Así, lo preincaico se diluye $\mathrm{y}$ amalgama después con lo incaico y éste, a su vez, se compenetra con el Derecho indiano con lentitud a partir de 1532 y luego adquiere gran dinamismo. La autoridad de los propios curacas será "occidentalizada" y utilizada inicialmente por los capitanes de esas huestes de Castilla y después por sas seguidores para sacar provecha de ella $\mathrm{y}$ satisfacer sus intereses crematisticos.

1.3. En el caso peruano hay una relación periférica: el derecho en sus origenes es aborigen como en Espanta y Portugal y después adquiere matices castellanos, y se vuelve primero indiano, occidental y después republicano (con sus vertientes que brotan en los manantiales romano, canónico, celta, germano, francés, español, alemán, brasilero, sajónico en algunos aspectos, que configuran el vasto sistema jurfidico peruano de hoy).

1.4. Esta evolución jurídica ha sido continua y recta en el Perú salvo el sủbito encuentro entre lo aborigen y occidental. En otros lugares no ha

(6) Las culturas preíncas son las de Chavin, Nazca.Paracns, Thahuanaco, entre otras. Puede consut tarse ef capitulo IX en ol jibro de Jorpo Basadre. Los fundumentos de la Historia del Derecho. Lima, 1956. (Hay dos ediciones posteriores). 
sucedido este fenómeno rectilíneo porque algunos sistemas jurídicos han sido sacudidos por invasiones de pueblos, culturas y razas diferentes y a veces antagónicas u opuestas entre sí. Veamos, por ejemplo, el caso de España que es una sucesión de aluviones raciales y jurídicos que han azotado lo que es hoy su territorio.

1.5. En Espafia, a diferencia del Perú, se han sucedido diversos periodos histórico-jurídicos: una época primitiva de celtas, iberos y mestizos de ambos llamados celtíberos, a la que siguió después la colonización de fenicios, griegos y cartagineses, entre otros. Todos estos pueblos sentaron influencias en el futuro derecho español que existe a partir de la abolición del derecho territorial con Felipe V.

El afio 218 A.C, marca el inicio del influjo romano en España por doble vía: como derecho provincial español nacido en la península ibérica y como Decreto clásico. En la forma de influencia jurídica no está comprendido "el que más tarde ejercita en Espafia el Derecho romano en su forma justiniánea y de las escuelas medioevales" en boga, ni en virtud de la dominación política, sino por medio del fenómeno llamado "de la recepción" (7).

Durante el siglo $V$ culmina el avance visigodo $y$ en donde surge la irradiación del Derecho germánico y visigodo. Este bagaje juriđico está constituido por un estatuto personal por el cual estos pueblos se rigen por sus principios jurídicos y las poblaciones españolas por sus leyes propias. Trátase de una etapa muy breve, ya que después se territoriatiza el Derecho y se generaliza para todos operándose la recepción del Derecho romano. El pueblo se manticne firme al Derecho y las costumbres germanas y entonces existe una lucha entre el Derecho germánico y consuetudinario y el germano-romano escrito de la monarquía visigoda. Esta batalla - lucha culmina con la victoria del derecho consuetudinario o derecho germano del pueblo porque se produce con la oleada de gentes musulmanes que se irradia en la idiosincracia espafola. La invasión árabe no influyb en forma gravitante sobre el Derecho hispánico.

La evolución de la España medieval fue un caso único en Europa. Un destino paradójico caracteriza a España desde la caída del imperio romano (7) Jorge Basndre. Histaria del Derecho Feruawa Lima, 1937, Capitulo Daodécino, (Hay edicio-
nes posteriores). 
hasta los conquistadores que hace cinco siglos duplicaron la superficie de los mundos conocidos y ensancharon el ámbito de la tierra.

La Edad Media española puede dividirse en dos fases. La más original va del siglo $\mathrm{V}$ al $\mathrm{X}, \mathrm{y}$ no tiene parecido en el resto de Europa ni con la peruana. En ella encontramos, del lado cristiano, el Derecho y las artes de los visigodos, de los asturianos y de los mozárabes. Del lado musulmán les sigue la eclosión, desde la invasión del afio 711 , de la brillante civilización árabe del emirato $\mathrm{y}$, luego, del califato omeyade de Córdova.

La segunda parte del milenio que termina poco antes del descubrimiento de América por Colón en 1492, abarca un periodo en el cual España se sitúa bajo la influencia de Italia (mundo romano) y de Francia (edad gótica). Castilla y Aragón conservan, sin embargo, su originalidad como focos de las ideas y de las culturas, gracias a los intercambios que mantienen con los reinos árabes de Andalucia. Estos últimos desempefan el papel de valiosos conservatorios del patrimonio legado por la antigüedad greco-romana y establecen un vinculo con las tradiciones del cercano oriente.

Este periodo medieval espafiol presenta constante característica conocida como la "Reconquista". Durante casi ochocientos años, los reinos cristianos del norte, en guerra contra el invasor árabe-bereber, van a recuperar con pérdida cuantiosa de sangre, las tierras ocupadas por los musulmanes. La reconquista sólo termina con la caída de Granada el 2 de enero de 1492, hecho que sella la expulsión de los moros.

Una vez que Espafia ha recuperado su unidad territorial, los reyes católicos pueden preparar algunos meses más tarde la expedición del navegante genovés que desemboca en el encuentro de dos mundos y sus gravitantes consecuencias.

El rol de España en esta aventura americana no es, en consecuencia, el fruto del azar: sólo una voluntad de unidad y la existencia de una serie de aportes científicos, culturales y tecnológicos, emanados de diversos horizontes, pueden conducir a ese resultado que transforma al mundo y marca el advenimiento de los tiempos modernos. La lucha de los vaivenes de la historia modelo el carácter del espaffol.

Tal es esta trayectoria que abarca diez siglos y que permite seguir la eclosión de una pluralidad artística y jurídica mucho más importante que la existente en la vecina Francia. Esta última no conoce el influjo ni 
de los visigodos, ni de los árabes omeyades, ni de los asturianos, ni de los mozárabes cuyas obras contribuyen a crear un clima muy particular en España aunque su irradiación jurídica es escasa en cuanto al influjo islámico.

Antes de que florezcan en el corazón de Europa las dinast fas carolingia y otoniana, y que Francia entre en gestación en la España sometida al invasor árabe-bereber, ocurre el comienzo de un movimiento de resistencia, Los cristianos se organizan en las montañas del norte de la peninsula y se niegan a pagar tributos. Luego tienen lugar escaramuzas con las fuerzas de ocupación islámicas.

Los primeros éxitos de los insurgentes devuelven la esperanza a un puñado de refugiados toledanos muy decididos a sacudirse del yugo musulmán. Quieren revivir el "glorioso orden de los godos". Porque los visigodos -esos llamados pueblos "bárbaros" asimilados culturalmente con rapidez poco después de las grandes invasiones- habian dado a España su precoz unidad territorial. Esta había permitido la propagación del "renacimiento" isidoriano, fase brillante por su nivel cultural y artístico, en comparación con el caos en que se debatía todavía el resto de Occidente. Es, pues, a los soberanos que reinaron en Toledo hasta el año 71 a quienes acatan los combatientes de la libertad. Perpetúan el ceremonial aúlico, los ritos, la escritura y el cómputo visigóticos, además de su influencia jurídica.

Espana, entonces, es testigo de la confluencia de diversas corrientes juridicas: celtiberas con sus nociones sobre el matrimonio solemne precedido de esponsales, el parentesco fundado en la línea materna, la propiedad gentilicia romana con las aplicaciones de los Derechos clásicos y vulgar, (mezcla con el Derecho indigena o aborigen); el árabe que no deja huellas trascendentales en el derecho castellano e influye en algunas instituciones y en el uso de términos jurídicos:y judias en menor grado. También tiene muy importantes raices de los ciclos romanos canónico que sientan las bases de un sistema romanesco y de la propia originalidad espanola, como el mayorazgo.

1.6. Esta confluencia de sistemas diversos no se da en el Derecho peruano, ni tampoco en el boliviano, brasilero o chileno, a manera de ejemplo. El caso español viene a ser especial y en el Perú no se produce este fenómeno de variedad de influjos extraños. Surge inicialmente en nuestro pais un Derecho aborigen, que no queda destruido totalmente, en 1523. Es mantenido en lo que no se oponga a la religión y a las normas 
mandatorias occidentales que, inclusive, se incluyen en el proceso codificador del siglo XIX. El derecho aborigen converge en el Indiano y éste en el republicano. La comunidad agraria sigue regulada por el Código Civil $y$ ha resistido el paso de los afios pese a su origen pre-inca.

E1 derecho peruano viene a ser una expresión de unidad y no una sección de etapas desunidas entre si. El profesor Manuel Belaunde Guinassi en la vinculación jurídica anotaba los elementos naturales siguientes: el territorio y la población. Y entre los elementos espirituales de vinculación histórica los siguientes: la religión, el idioma y las expresiones culturales (8).

1.7. Deben anotarse, igualmente, elementos jurídicos en estos vínculos formativos que son dos: a) el aporte y la supervivencia de costumbres, instituciones $y$ formas juridicas aborigenes incorporadas al Derecho peruano; y b) la extensión, la aplicación y el aporte del Derecho occidental (castellano, romano, germano, canónico, europeo y anglosajón en menor grado). Y, con todos estos simbolos formativos se ha generado un sistema jurídico propio que se gesta on la conjunción de los derechos aborigen y occidental, respectivamente.

\section{LA EVOLUCION DEL DERECHO PERUANO Y CRITERIOS PARA SU PERIODIFICACION}

El vocablo derecho, como es conocido, tiene incidencias sobre diversos objetos: la ley, la doctrina, el fallo o la resolución judicial y administrativa, la ciencia jurídica y su enseñanza, la costumbre y la príctica. Y con la expresión peruano se está entendiendo el Estado patrio para fijar el ente político y jurídico llamado "Penú" desde su audaz salto al vacio que es la republicana y representativa el 28 de julio de 1821 . Pero, el origen de este sistema juridico republicano que será a partir de esa fecha, devendrá en escrito, será prolífico en constituciones políticas iniciales y después con tendencia a la codificacion, representativo y contradictorio en muchas de sus disposiciones y atrasado con relación al sistema europeo, imitador de éste en el siglo XIX con los textos comerciales y penales, y en la ley hipotecaria aparecida después de la guerra del Pacífico.

(8) Manuel Beiaunde Guinassi. Arograma razonado de Histarie del Derecha Penueno, Lima, 1961. p. 10. 
2.1. El Perú no es sólo una situación republicana reciente sin raíces en el pasado. Existió antes de estas fechas epocales de la era independentísta en un proceso histórico milenario habido en su suelo y, como quedó dicho, el enfrentamiento de las culturas indígena y castellana germinará en un nuevo sistema que es el indiano.

El Derecho peruano no se inicia con el nuevo orden jurídico que aparece el 28 de julio de 1821 . Siguió rigiendo, a partir de ese acto ejecutado por San Martín ante el pueblo, toda la variada y frondosa legislación española junto con motines, asonadas, cuartelazos y aventuras belicas hacia Colombia y Bolivia. Se compulsaron inicialmente varias opciones políticas diversas a adoptarse para la naciente república: la monarquía, la unión o fusión con otras repúblicas, la dictadura, La república aparece recién irradiada en su desarrollo posterior en el año 1842.

2.2. A fin de establecer las etapas diversas en la evolución histórica del Derecho peruano, pretendemos trazar un criterio mixto histórico-juridico que coincida en alguna forma con la clasificación hístóricocronológica. Esta periodifiçación se hace, sólo con fines diđácticos, en la forma siguiente:

D. Epoca o periodo autóctono, aborigen o de Derecho oral: hasta fines del siglo XV o principios del siglo XVI que comprende las culturas preincas e incas.

II). Epoca o periodo del Derecho escrito (siglo XVI a la fecha).

1). Derechos en las etapas conccidas como del descubrimiento $\mathrm{y}$ conquista (fines del siglo $\mathrm{XV}$ y principios del XVD).

2). Derecho virreynal y colonial o hispánico o indiano (siglos XVI, XVII, XVIII y principios del siglo XIX) (9).

Esta etapa comprende la transferencia del Derecho de Castilla a las Indias $y$ la formación $y$ aplicación del Derecho indiano, cuya extensión puede hacerse en la siguiente forma:

(9) In Academia Nacional de Histeris de Argentina, en octubre de 1948, y a iniciatha de don Ríardo Levene, acogió sustituir la expresión periodo colomial por el de poriodo hispano. 
a. Inicial (de las capitulaciones de Toledo de 26 de julio de 1529 a 1542).

b. De organización del Derecho virreinal (1542-1596)

c. De la elaboración de la recopilación de 1680 (1596-1680).

d. De la aplicación de la recopilación (1680-1792).

e. De las transformaciones politicas y sociales con motivo de la dinastia bortónica y su decadencia (1792-1821).

\section{3). Derecho republicano}

a. Periodo intermedio (1821-1852) (10).

b. Periodo codificado (1852 a nuestros días).

\section{LA FUERZA INTEGRANTE DEL TERRITORIO EN LA HISTORIA DEL DERECHO PERUANO}

La república peruana se erigió en 1821 sobre las bases territoriales del virreinato del Perú: sirvieron de pauta los hitos limitrofes de éste en 1821, enmarcados por las jurisdicciones de las audiencias de Lima y Cuzco. El principio rector fue el uti possidetis, de acuerdo al estado posesorio del af́o 1810 , en que arranca el movimiento independentista de América. El Perú empezó el salto al vacío que representó la forma republicana y representativa en su azarosa existencia tomada por la libre determinación popular con los consiguientes límites mutilados por obra de la administración colonial borbónica: por el norte, la república de Colombia que después se dividió en las repúblicas de Ecuador, Venezuela y Colombia; tomándose como base las audiencias de Quito y Nueva Granada; por el oeste, con el Imperio del Brasil, conforme a la demarcación del tratado de San Ildefonso de 1777 entre Espana y Portugal; por el sur, el virreinato penuano lindaba con el de Buenos Aires y con la guerra de la independencia se creó la república de Bolivia (11). El Pení no limi-

(10) Se utiliza la expresión de Derecho intermedio para precisar el conjunto de đisposictones públicas y privadas dictadas par los gobjetnos argentinos entre 1810 y 1853 . Eate término es splicable al Derecho peruano precodificado en is Repóblica.

Puede consultarse el tibro de Daniel Antokcletz titulado Histarie del Derecho Argentina Derecho Castellano - Derecho indígena - Derecho Indiano - Derecho Argentino). Buenos Aises, 1929, tomo II. p. 193.

(I1) Jorpe Hasadre. Historia de la Republice del Pent, 1822-1933. Sétims edición, Tomo L. pp. 133 y $\mathrm{ss}$. El capitulo es el pertinente a los límites con Bolivia. Segin el autor de este bibro, la creación de la república boliviana importó una naeva ruptura con el principio de "uti possidetis" de 1810. En casnto n las "desarticuladas bases geogrificas administrativas, económicas y hacendarias de la primera república del Pesá" paede consultarse el Capítulo VIII. Jorge Basadre, Op, cit, tomo I, p. 133 y ss. 
taba con Chile al erigirse en república independiente sino con Bolivia. La guerra de 1879 hizo que el territorio peruano lindara con el chileno, con lo que apareció un nuevo vecino en nuestra vida republicana.

El territorio peruano apareció notoriamente recortado en el inicio republicano comparado con la extensión incaica y después de la creación del virreinato. Con la unificación del imperio incaico los límites del Tahuantinsuyo llegaban, por el norte, hasta el río Ancasmayo, y que corre entre los confines de Quito y Pasto; al medio día, tenía por término el río Maule pasado el reino de Chili, antes de llegar a los araucos; $y$, al levante, tenia "las tierras nunca jamás pisadas de hombres, ni de animales, ni de aves, inaccesible cordillera de nieves que corre desde Santa Marfa hasta el estrecho de Magallanes... y tal poniente confina con el mar del sur que corre por toda la costa de largo a largo" (12).

Como lo ha expresado Jorge Basadre, el Perú empezó a vivir la República con la herencia desmembrada por los borbones en el siglo XVIII y por la guerra de la independencia; sufriendo, a lo largo de su historia, de otras grandes mutilaciones territoriales con Brasil, Colombia y Chile (13).

\section{LA FUERZA INTEGRANTE DE LA RELIGION}

La religión ha constituido una fuerza espiritual histórica. La llegada de las huestes de Castilla al nuevo continente inició la propagación de la doctrina de la Iglesia Católica, apostólica y romana y que la vasta legisla. ción indiana recoge.

Producida la independencia, los ideólogos de la nueva república concibieron abrir el camino de la libertad religiosa. El Congreso constituyente del año 1822 aprobó la declaración de que la religión de la nación "era

(12) Gerdlaso de la Vega Comentarion Resles. Libro I, Capítulo VIII.

(13) Sobre el tema de la historia tina itrofe del Perú existe variada bibliografia, En una visión orgh. nica estí la Histeria de la Repriblica del Prni, cat, hasta el gobieme de Luis M. Ś́nchez Cerro. Adernás, paeden consultame los libros de Juan Angulo Raeate Amsa. Historia de los limaites def Ani. Lims, 1924 y 1929; Raúl Porras Barrenochea. Hirtorie de los Ilmites del Peni.

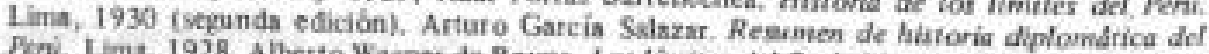
Peni, Limi, 1928. Alberto Wagner de Reyns. Los limites del Peni. Lima, 1961 iy, Raúl Porrs Banenechea -Aberto Wagner de Reyna. Itistorie de los limites del Feni. Lima, 1981. Pars une hithliogafia de la histocis internacional y diplomitica penerst puede consultarse la Inta consigada en Joage Busadre, Introdiección a lar bases documentales para la historia de la Republico del Peri con alganas reflexianes. Lima, 1971, tomo 1, Dp. 159 y ss. 
la Católica, Apostólica y Romana " con lo que se declaraba implícitamente la libertad religiosa. Pero, el 30 de noviembre de 1822, es decir, al día siguiente de esta declaración, fue presentado un memorial suscrito por vecinos notables de Lima solicitando se anexe a este artículo las palabras "con exclusión de otra alguna". En virtud de esta petición, se reabrió el debate agrio de la libertad de cultos y se aprobó la edición en estos términos: "con exclusión de cualquiera otra". La constitución politica del año 1822 sancionó la intolerancia religiosa.

4.1. En las constituciones políticas posteriores, de los años 1828 y 1834 , la declaración sobre libertad de cultos estaba consignada con esta frase: "su religión es Católica, Apostólica y Romana: la Nación protege por todos los medios conforme al espíritu del Evangelio y no permite el ejercicio de otra alguna". La prohibición comprendía el ejercicio del culto sin distinguir el público del privado por lo que la intolerancia era llevada hasta el extremo. Este temperamento se modificó en la Constitución del å̃o 1839 y la prohibición ya se limitó al ejercicio público de cualquier otro culto. En la carta de 1860 se suprimieron las palabras: " $y$ no permite el ejercicio público de otra alguna" y, asi, se recepcionó en el artículo 5 de la Constitución del oncenio de Leguía en el siglo XX. La carta vigente permite la libertad de cultos.

4.2. No obstante las libertades de cultos, la Iglesia Católica no ha cesado en su influencia en la producción jurídica peruana. Así, el divorcio vincular apareció con notoria tardanza por obra del gobiemo de Luis $\mathbf{M}$. Sánchez Cerro, como una reacción contra el régimen cesante que habia sido sumiso a la Iglesia Católica por once affos. Tanto el divorcio vincular como la separación de cuerpos por mutuo disenso, capaz de convertirse también en una resolución que disolvía el vínculo matrimonial, se introducen en el Código Civil de 1936 (14) (15).

(14) "El cleto a lo largo del sido XX se había encerrado dentro de una intrassigencia ultramontana y en el ambiente público ers visible un retroceso de las ideas Eberales". Jorge Basadre. Historia de la Repuiblica del Ferí 1822-1933, Lima, 1983, tomo 1, p. 177.

(15) El Decreto-Ley 6889 establestó el matrimonio civil obligatorio, El Decreto-Ley 6890 reglamentó el divorcio. Estos textos fueron ratificados por la Ley 7893. 